\title{
The Correlation Between Hematoma Volume and Outcome in Ruptured Posterior Fossa Arteriovenous Malformations Indicates the Importance of Surgical Evacuation of Hematomas
}

\author{
Rüptüre Posterior Fossa Arteriovenöz Malformasyonlarda Hematom \\ Volümü ile Klinik Sonuç Arasındaki İlişki ve Hematomun Cerrabi \\ Tedavisinin Önemi
}

Adem YILMAZ ${ }^{1}$, Ahmet Murat MUSLUMAN ${ }^{1}$, Ayhan KANAT ${ }^{2}$, Halit CAVUSOGLU ${ }^{1}$, Yuksel TERZI ${ }^{3}$, Yunus AYDIN ${ }^{1}$

${ }^{1}$ M.H. Sisli Etfal Research and Education Hospital, Department of Neurosurgery, Istanbul, Turkey

${ }^{2}$ Rize University, Faculty of Medicine, Department of Neurosurgery, Rize, Turkey

${ }^{3}$ Ondokuz Mayis University, Faculty of Medicine, Department of Statistics, Samsun, Turkey

Correspondence address: Adem YILMAZ / E-mail: ademyilmaz70@yahoo.com

\begin{abstract}
AIM:The correlation between hematoma volume and outcome in ruptured arteriovenous malformations (AVM) with accompanying posterior fossa hematoma was retrospectively evaluated.

MATERIAL and METHODS: Microsurgery operations were performed on 127 patients with intracranial AVM between January 1998 and January 2009 at our clinic. Fifteen (11.8\%) patients were identified as suffering from posterior fossa AVM, and twelve of these patients presented with a cerebellar hematoma. All patients were clinically evaluated according to the following criteria: modified Rankin Scale (mRS) prior to surgery, Spetzler-Martin grade (SMG) of the AVMs, hematoma volume prior to surgery, and mRS following surgery.

RESULTS: Postoperative $m R S$ scores were significantly lower than preoperative scores $(p=0.0001)$. Postoperative outcomes were concordant with the SMG of the AVMs $(r=0.67, p=0.033)$, hematoma volume $(r=0.537, p=0.072)$ and preoperative mRS scores $(r=0.764$, $p=0.004)$. These analyses show that the postoperative mRS score is strongly correlated with a preoperative mRS score, hematoma volume and SMG.

CONCLUSION: Posterior fossa AVMs present an increased risk for hemorrhage and for increased morbidity and mortality. Cases with hematoma should be operated on an urgent basis. We conclude that hematoma volume is a factor that impacts postoperative results and prognosis. SMG and preoperative mRS scores were also correlated with outcome.
\end{abstract}

KEYWORDS: Arteriovenous malformation, Intracerebellar hemorrhage, Micro-surgery, Posterior fossa

öz

AMAÇ: Rüptüre posterior fossa arteriovenöz malformasyonlarda hematom volümü ile klinik sonuç arasındaki illişki retrospektif olarak değerlendirildi.

YÖNTEM ve GEREÇ: 1998 ile 2009 arasında kliniğimizde 127 hasta intrakranyal arteriovenöz malformasyon nedeniyle mikrocerrahi ile ameliyat edildi. Bu hastaların 15 tanesi $(\% 11,8)$ posterior fossa AVM'si idi. Bu Serebellar AVM li hastaların da 12'si serebellar hematoma ile başvurdu. Serebellar hematomlu AVM hastalarının; ameliyat öncesi modifiye Rankin Skalası (mRS), Spetzler-Martin grade (SMG) ve hematom volümü, ameliyat sonrası modifiye Rankin Skalası ile karşılaştırmalı olarak değerlendirildi.

BULGULAR: Postoperatif $m R S$ skoru istatistiksel olarak anlamlı şekilde preoperatif skordan daha düşük bulundu $(p=0,0001)$. Postoperatif klinik sonuç; AVM'nin SMG'l $(r=0,67, p=0,033)$, hematom volümü $(r=0,537, p=0,072)$ ve preoperatif $m R S(r=0,764$, $p=0,004)$ ile uyumlu bulundu. Nörolojik defisit AVM'nin SMG'i ile uyumlu şekilde artmış idi. İncelemeler göstermektedir ki, postoperatif mRS, preoperatif mRS, hematom volümü ve SMG ile daha fazla ilişkilidir.

SONUÇ: Posterior fossa AVM ler, kanama riski ile beraber artan morbidite ve mortalite riski taşıyan kompleks nörovasküler lezyonlardır. Hematomlu vakalar acil şekilde opere edilmelidir. Hematom volümü klinik sonuç ile ilişkidir. Biz hematom hacminin, postoperatif klinik sonuç ve prognoz üzerinde etkili bir faktör olduğu sonucuna vardık. Ayrıca preoperatif SMG ve mRS de klinik sonuç üzerinde etkilidir.

ANAHTAR SÖZCÜKLER: Arteriovenöz malformasyon, İntraserebellar hemoraji, Mikrocerrahi, Posterior fossa 


\section{INTRODUCTION}

Posterior fossa arteriovenous malformations (AVMs) supplied by the vertebrobasilar system are traditionally regarded as rare lesions and originally thought to comprise only $7-15 \%$ of malformations in the major series of patients $(3,25)$. Multivariate analyses targeted at elucidating the relationship between infratentorial location and hemorrhagic presentation have found that posterior fossa AVMs are more likely to present with hemorrhagic or cerebellar findings and are rarely accompanied by seizures $(3,8,9,14,21,28,31)$. However, there seems to be no general agreement on the selection of treatment modality for individual patients, and to our knowledge, no reports have been published on infratentorial AVM cases accompanied by a cerebellar hematoma. The purpose of the present study was to test the correlation between hematoma volume and outcome in ruptured arteriovenous malformations.

\section{MATERIAL AND METHODS}

\section{Patients}

During an 11-year period between January 1998 and January 2009 at the Sisli Etfal Training and Research Hospital Neurosurgery Clinic, 127 microsurgery operations were performed on patients with intracranial AVM. Among these patients, fifteen (11.8\%) were identified as suffering from a posterior fossa AVM. Twelve of these fifteen patients displayed cerebellar AVM accompanied by cerebellar hematoma (Figure 1A-F, 2A-F). Patients were between 19 and 57 years of age (mean 28.3 years). Seven of the cases $(58.3 \%)$ were male, and five $(41.7 \%)$ were female. Left and right cerebellar hemorrhages were present in $8(66.6 \%)$ and $4(33.4 \%)$ of the cases, respectively (Table I).

\section{Protocol}

Our management protocol was based on the degree of 4 th ventricular compression, hematoma volume observed on the initial computed tomography (CT) scan, and the GCS score at the time of treatment. Magnetic resonance imaging (MRI) and digital subtraction angiography (DSA) were performed on all patients. The appearance of the fourth ventricle adjacent to the hematoma, based on CT scans, was divided into the following three grades: Grade 1: normal, Grade 2: compressed, and Grade 3: disappeared (completely effaced). Various features on the first CT scan following presentation were also evaluated, including the presence or absence of hydrocephalus, the location of the hematoma (whether occupying the cerebellar hemisphere or the vermis) and the presence or absence of intraventricular hemorrhage. The volume of the hematoma was measured by calculating the area occupied by the hyperdense hematoma on each slice of the CT images and multiplying the area by the thickness of each slice. Volume was calculated according to the dimensions measured in the axial CT scans (height $x$ width $x$ length $x$ 0.5). AVMs were classified according to the Spetzler-Martin Grading (SMG) system. Hematoma volume and Glasgow coma score (GCS) also affected the surgical decision. Urgent surgery was suggested according to the following criteria: all Grade 3 hematomas, Grade 2 hematomas with GCS $\leq 10$, or size of hematoma $>3 \mathrm{~cm}$.

\section{Surgical Method}

All patients were operated on using a midline or paramedian suboccipital craniectomy and the microsurgical technique by the senior author (YA) and were monitored at the intensive care unit. The surgical technique used was similar to the supratentorial craniotomy. AVMs and the underlying parenchyma were first inspected to identify the superficial arterial inflow and venous outflow, which are correlated with the preoperative MRI and angiogram. Dissection was facilitated by the gliotic plane, which usually forms between the AVM and normal parenchyma, as well as by previous hemorrhage cavities. Care was taken to spare large veins draining the vascular malformation, with dissection often continuing under or around such vessels. Following complete dissection of the AVM and interruption of all arterial inflow, venous drainage can then be safely divided and the AVM removed.

Routine cranial CT scans were performed 48 hours following the operation for standardized documentation of treatmentrelated complications. Any residual AVM was investigated within two weeks of surgery by DSA and MRI. Follow-ups occurred regularly for all patients at intervals of 1,6 , and 12 months and annually thereafter. The mean follow-up period for patients was 32 months (between 1 and 9 years).

Patients were assessed according to a modified Rankin Scale (mRS) prior to and following surgery: mRS Grade 0: no symptoms, Grade 1: no significant disability, Grade 2: slight disability, Grade 3: moderate disability, Grade 4: moderate severe disability, Grade 5: severe disability, or Grade 6: death. A favorable outcome was defined as an mRS score of 0,1 or 2. Morbidity was defined as an mRS score of 3,4 or 5 (moderate to severe neurological disability) during the first postoperative year.

The correlations of post-operative mRS scores with preoperative mRS scores, Spetzler Martin Grading and hematoma volume were assessed.

\section{Statistical analysis}

Statistical analyses were carried out with a NCSS 2007 package program. To statistically evaluate descriptive data (average, standard deviation) as well as preoperative and postoperative mRS assessments, the Wilcoxon test was applied to determine the relationship between variables where the Spearman correlation test was used. Results and significance levels were assessed. Significance was defined as $p<0.05$.

\section{RESULTS}

The distribution of the AVM feeding vessels is shown in Table I. In 5 patients, the feeding artery was the superior cerebellar artery (SCA); in 3 patients, it was the SCA and anterior inferior cerebellar artery (AICA); and in 1 patient, it 
Table I: Common Characteristics of Patients

\begin{tabular}{|c|c|c|c|c|c|} 
Case no & Age/gender & Localization & Feeding artery & Venous drainage & $\begin{array}{c}\text { AVM size/ } \\
\text { hematoma volume }\end{array}$ \\
\hline 1 & $30 / \mathrm{m}$ & Left cerebellar & SCA & Inferior hemispheric vein & $2 \mathrm{~cm} / 14 \mathrm{~cm} 3$ \\
\hline 2 & $22 / \mathrm{m}$ & Left cerebellar & SCA & Transverse sinus & $1 \mathrm{~cm} / 4 \mathrm{~cm} 3$ \\
\hline 3 & $31 / \mathrm{m}$ & Right cerebellar & Meningotentorial & Internal cerebral vein & $6.5 \mathrm{~cm} / 36 \mathrm{~cm} 3$ \\
\hline 4 & $26 / f$ & Right cerebellar & SCA & Superior petrosal sinus & $2 \mathrm{~cm} / 14 \mathrm{~cm} 3$ \\
\hline 5 & $48 / \mathrm{m}$ & Left cerebellar & PICA & Transverse sinus & $4 \mathrm{~cm} / 21 \mathrm{~cm} 3$ \\
\hline 6 & $24 / \mathrm{f}$ & Left cerebellar & SCA, AICA & Superior petrosal sinus & $3.5 \mathrm{~cm} / 14 \mathrm{~cm} 3$ \\
\hline 7 & $28 / \mathrm{m}$ & Left cerebellar & SCA & Internal cerebral vein & $2 \mathrm{~cm} / 15 \mathrm{~cm} 3$ \\
\hline 9 & $19 / \mathrm{f}$ & Right cerebellar & PICA, AICA & Thalamostriate vein & $3.5 \mathrm{~cm} / 20 \mathrm{~cm} 3$ \\
\hline 10 & $23 / \mathrm{m}$ & Left cerebellar & SCA, AICA & Transverse sinus & $1 \mathrm{~cm} / 6 \mathrm{~cm} 3$ \\
\hline 11 & $32 / \mathrm{m}$ & Right cerebellar & SCA & Transverse sinus & $4 \mathrm{~cm} / 26 \mathrm{~cm} 3$ \\
\hline 12 & $57 / \mathrm{m}$ & Right cerebellar & ECA, OCCipital branch & Transverse sinus & $2 \mathrm{~cm} / 15 \mathrm{~cm} 3$ \\
\hline
\end{tabular}

$\mathbf{S C A}=$ superior cerebellar artery, $\mathbf{P I C A}=$ posterior inferior cerebellar artery, $\mathbf{A I C} \boldsymbol{A}=$ anterior inferior cerebellar artery, $\mathbf{E C A}=$ external carotid artery

was the AICA and posterior inferior cerebellar artery (PICA) as well as the meningotentorial and occipital branches of the external carotid artery. The distribution of AVMs according to venous drainage is shown in Table I. In 6 cases, drainage was through the transverse sinus; in 3 cases, it was through the superior petrosal sinus; and in 1 patient, it was through the inferior hemispheric vein, deep cerebral vein and strait sinus. Aneurysms were not an accompanying finding in any of these cases.

The mean duration of bleeding prior to surgery was 7.3 days (between 1 and 11 days). The sizes of the cerebellar hematomas ranged from $2 \mathrm{~cm}$ to $7 \mathrm{~cm}$. The degree of fourth ventricular compression was correlated with the size and volume of the hematoma and the presenting GCS score.

As determined by the degree of compression in the 4th ventricle, cerebellar hematomas were assessed as Grade I in 4 cases, Grade II in 6 cases and Grade III in 2 cases. Two patients with Grade III hematoma were operated upon immediately. Due to the development of hydrocephaly in a patient with a Grade II hematoma and a progressive neurological deficit in another patient with a Grade II hematoma, these patients were operated on on Day 2 and Day 3, respectively. The eight remaining cases were operated on between the tenth and thirteenth day of bleeding. The mean total period of the operation was between 3 and 7 hours. Postoperative hydrocephaly developed in 2 patients with Grade 3 hematomas, whereas a shunt was inserted in another. No shunt was required in the other patient, however, due to the moderate degree of his hydrocephaly.

Based on the SMG system, four cases were assessed as Grade I (33.3\%), five cases as Grade II (41.6\%), two cases as Grade III (16.6\%) (Figure 2A-F), and one case as Grade IV (8\%) (Figure
$1 \mathrm{~A}-\mathrm{F})$. No cases were assessed as Grade V (0\%) (Table II). After thorough investigation of patients' control angiograms, it was observed that eleven AVMs were totally excised. One case with a residual AVM was treated using a gamma knife.

Table III shows the clinical outcome of 12 patients according to the $\mathrm{mRS}$ at postoperative month 32. In preoperative assessments, 7 cases (58.5\%) had favorable outcomes, and in

Table II: Classification According to the Spetzler-Martin Grading System

\begin{tabular}{|c|c|}
\hline AVM diameter & No. \\
\hline Small $(<3 \mathrm{~cm})$ & 7 \\
Medium $(3-6 \mathrm{~cm})$ & 4 \\
Large $(>6 \mathrm{~cm})$ & 1 \\
\hline Deep venous drainage & \\
\hline None & 9 \\
Yes & 3 \\
\hline Eloquent locations & \\
\hline None & 9 \\
Yes & 3 \\
\hline Spetzler- Martin score & 4 \\
1 & 5 \\
2 & 2 \\
4 & 1 \\
5 & 0 \\
\hline
\end{tabular}


Table III: Summary of Pre- and Postoperative Neurological Impairment and Improvement in 12 Patients According to Modified Rankin Scale (mRS)

\begin{tabular}{|c|c|c|c|c|c|c|c|c|c|}
\hline \multirow[b]{2}{*}{ Late postoperative mRS } & \multicolumn{7}{|c|}{ Preoperative mRS } & \multirow[b]{2}{*}{$(\%)$} & \multirow{2}{*}{$\begin{array}{c}\text { Totals } \\
\text { (\%) }\end{array}$} \\
\hline & 0 & 1 & 2 & 3 & 4 & 5 & 6 & & \\
\hline $0=$ no symptoms & & & & & & & & 0 & \\
\hline $1=$ no significant disability & & 1 & 5 & 2 & & & & 67 & 92 \\
\hline 2 = slight disability & & 1 & & 1 & 1 & & & 25 & \\
\hline $3=$ moderate disability & & & & & 1 & & & 8 & \\
\hline \multicolumn{10}{|l|}{$4=$ moderate severe disability } \\
\hline $5=$ severe disability & & & & & & & & & 8 \\
\hline \multicolumn{10}{|l|}{$6=$ death } \\
\hline$(\%)$ & 0 & 16.5 & 42 & 25 & 16.5 & 0 & 0 & 100 & \\
\hline Totals (\%) & & 58.5 & & & & 41.5 & & & \\
\hline
\end{tabular}

5 cases $(41.5 \%)$, morbidity was defined as an mRS score of 3 and 4 (moderate to severe neurological disability). During the postoperative term, no mortality was present. Assessments of the overall first year clinical outcome showed an outcome (mRS score $0-2$ ) in 11 (92\%) of the patients. A worse outcome was defined as an $\mathrm{mRS}$ score $>2$, which occurred in only one patient (8\%).

Postoperative mRS scores were significantly lower than preoperative scores $(p=0.0001)$. Postoperative neurological outcomes were compared according to the SMG. Postoperative outcomes were concordant with the SMG of the AVMs (Spearman test $r=0.896, p=0.0001),(r=0.75$, $p=0.012$ ), and neurological deficits increased in correlation with the SMG of the AVMs. Postoperative outcome was also concordant with hematoma volume $(r=0.537, p=0.072)$ and preoperative $\mathrm{mRS}$ scores $(r=0.764, \mathrm{p}=0.04)$.

\section{DISCUSSION}

The aim of this study was to review the existing evidence supporting surgical evacuation of AVM hematomas in the posterior fossa. In the absence of clinical trials on this field, data derived from clinical series suggest that the level of consciousness, the size of the hematoma, the presence of hydrocephalus and the compression of the posterior fossa CSF-containing spaces are the main criteria to be considered when deciding case management. Fourth ventricle compression seems to be the best indicator of the last of these parameters $(3,22)$.

\section{Current management}

Current treatments for AVMs include microsurgical resection only, preoperative endovascular embolization followed by microsurgical resection, stereotactic radiosurgery only, preprocedural endovascular embolization followed by radiosurgical treatment, endovascular embolization only, and observation only $(3,13,14,31)$.

\section{Microsurgery}

In AVM cases with a history of hemorrhage, microsurgery must be the primary and preferred method to protect the patient from re-bleeding and progressive neurological damage. Microsurgical resection, when it can be performed safely, is the gold standard treatment for posterior fossa AVM with hematoma. It has two advantages: the evacuation of the devastating hematoma and the excision of the AVM $(3,14,25)$. AVMs with posterior fossa hematomas, because of their localization, may require urgent evaluation and surgical intervention. Previous data suggest that hematomas less than $3 \mathrm{~cm}$ in size and without fourth ventricular compression can be managed conservatively or by means of ventricular drainage if hydrocephalus exists and requires treatment $(3,14,22,25)$. Accordingly, we urgently operated upon 4 patients on either the same day ( 2 patients) or on the 2 nd and 3 rd days ( 2 patients). The remaining eight cases were operated on the ten to thirteenth days of bleeding.

In some special situations, other therapeutic techniques may be helpful. There is certainly a well-established role for adjunctive endovascular embolization of some AVMs. Clearly, there are also specific situations, such as small, deep AVMs in delicate brainstem structures, in which microsurgery should not be used as the primary treatment modality; stereotactic radiosurgery and occasionally embolization (if there is reasonable expectation of complete obliteration by embolization) are the preferred treatment options in these cases $(7,22,25,30,36)$.

\section{Infratentorial AVM hemorrhage}

Infratentorial AVMs are more likely to be present with hemorrhage, and rarely present with seizures. Within six combined, large surgical series, 207 (84\%) of 246 patients harboring infratentorial AVMs presented with a hemorrhage $(3,8,14,23,26,31)$. Khaw et al. (15) demonstrated that 


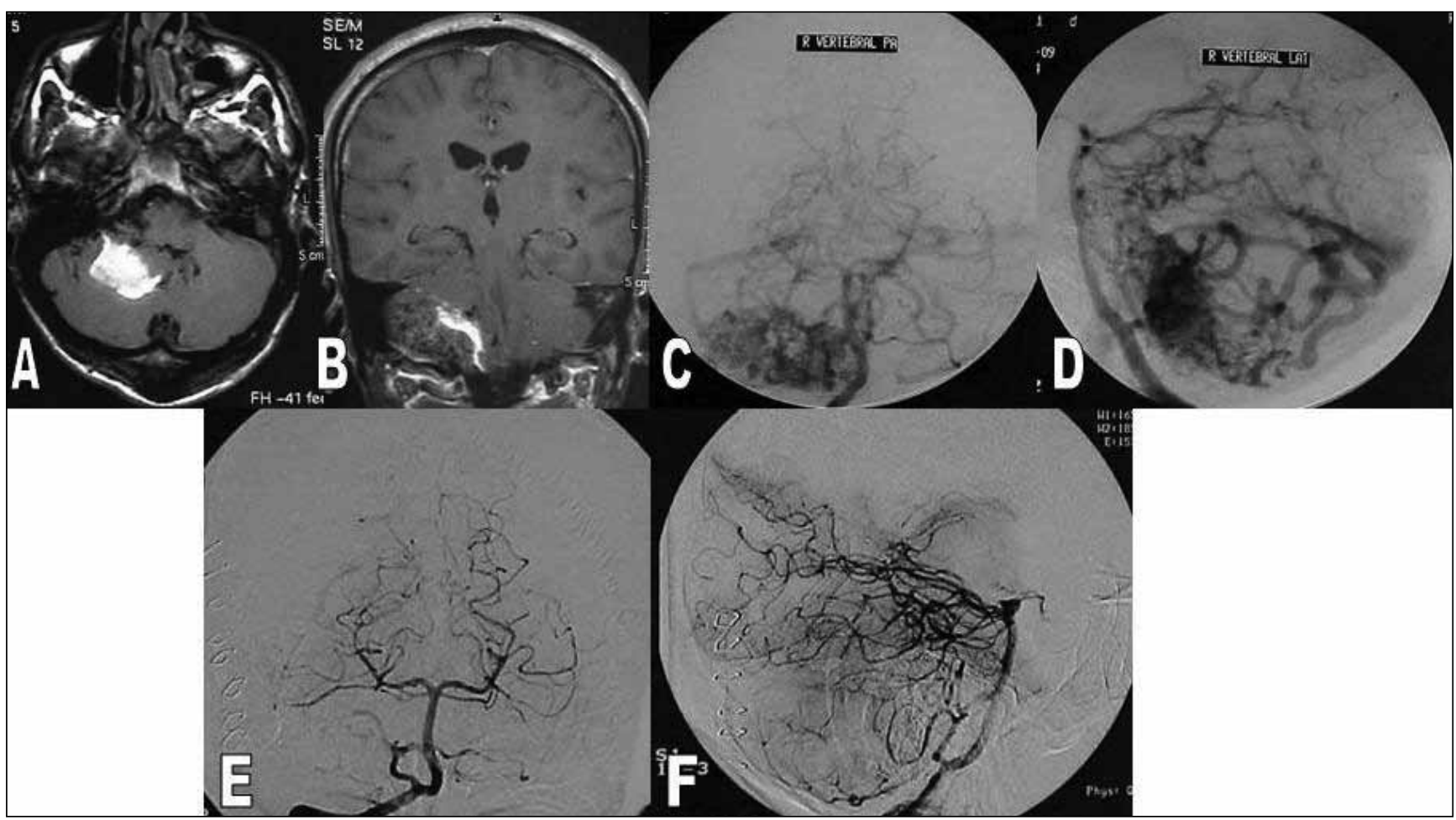

Figure 1: Preoperative axial A), and coronal B) MRI and angiography of the right vertebral artery C,D) of Case 3 showing a SpetzlerMartin Grade 4 AVM. Postoperative angiography of the vertebral artery E,F) showing complete removal of the AVM.

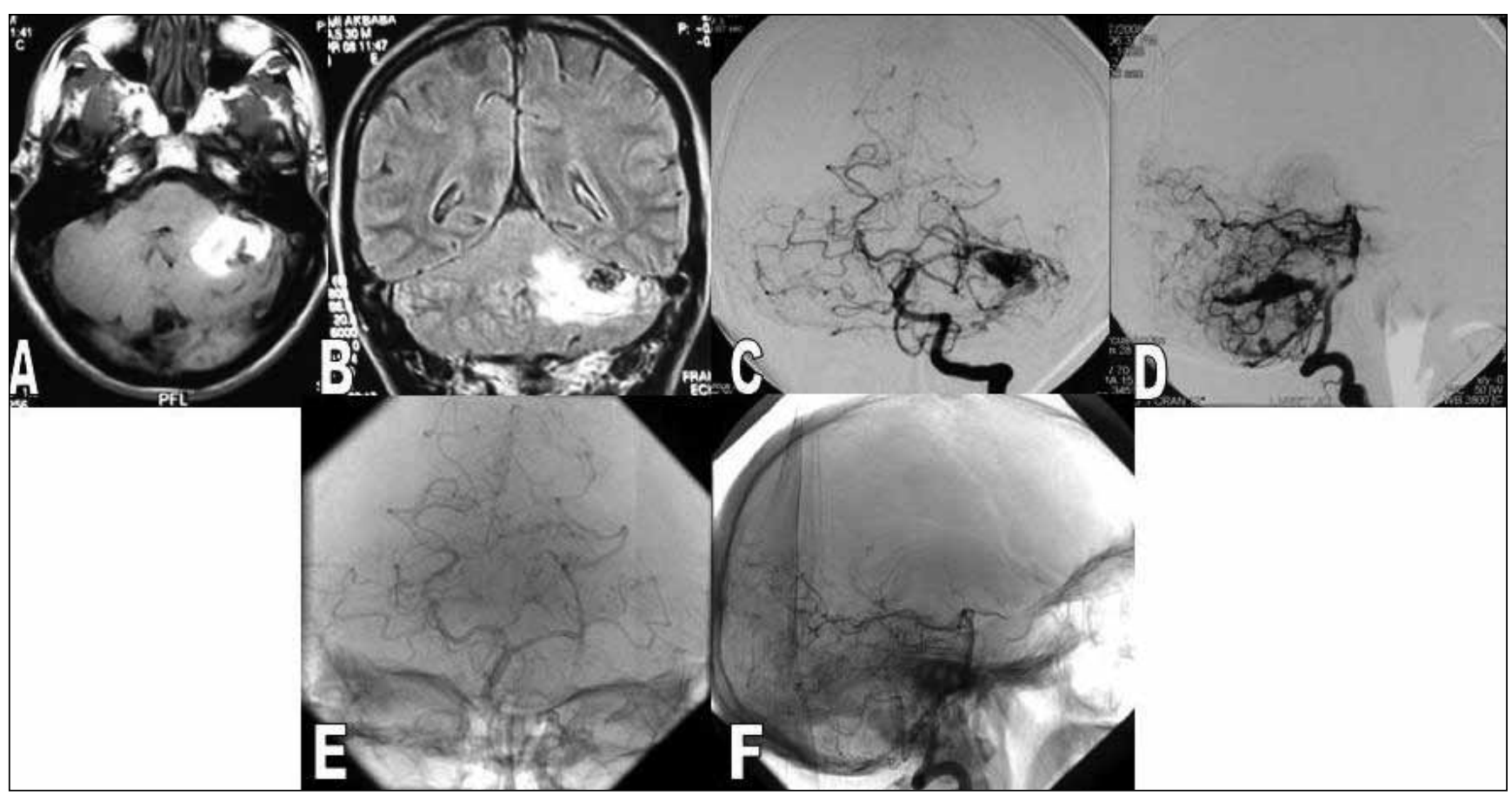

Figure 2: Preoperative axial A), coronal B) MRI, and angiography of the left vertebral artery C,D) of Case 1 showing Spetzler-Martin Grade 3 AVM. Postoperative angiography of vertebral artery E,F) showing complete removal of the AVM. 
infratentorial AVMs were almost twice as likely to present with a hemorrhage as supratentorial AVMs. Similarly, in the Toronto Study Group (29), 21 (60\%) of 35 patients with infratentorial AVMs presented with a hemorrhage compared with 125 (35\%) of 355 patients with supratentorial AVMs and 88 (29\%) of 299 patients with superficial AVMs. In another study, 36 (86\%) of 42 patients with infratentorial AVMs presented with hemorrhage compared with 221 (54\%) patients out of 407 with supratentorial lesions (5). In our study, of the 15 patients (11.8\%) identified to harbor posterior fossa AVMs, 12 (80\%) were admitted with hemorrhage. The hemorrhage ratio was $66(58.9 \%)$ out of 112 supratentorial AVM patients.

\section{Hematoma volume}

Hematoma volume is a significant factor in surgical indications. Usually, authors state that they operate on patients who have hematomas larger than $3 \mathrm{~cm}$ in size and greater than $15 \mathrm{ml}$ in volume $(5,16)$. In this study, cerebellar hematomas resulting from ruptured AVMs were present in all 12 cases. When blood volume and clinical status were considered, four cases underwent urgent surgery. The degree of fourth ventricular compression was correlated with the size and volume of the hematoma and the presenting GCS score.

\section{Compression of the fourth ventricle}

We reemphasize that the management protocol in this study of ruptured AVMs accompanied with posterior fossa hematomas was based on the initial CT appearance following hemorrhage. Severe compression of the fourth ventricle (Grade III) on the initial CT scans was associated with low GCS scores at presentation and poor outcomes (33). The fourth ventricular appearance grades were well-correlated with hematoma volumes and clinical courses. Areas of swelling surrounding hematomas or exerting mass effects would also affect the fourth ventricular grade. These findings indicate the possible value of this radiological sign as an indicator of the degree of brainstem compression. Some authors regard the hydrocephalus that results from the AVM as an indication of brainstem compression $(19,32,34)$. In this study, cerebellar hematomas were assessed as Grade I in four cases, Grade II in 6 cases or Grade III in 2 cases according to compression of the 4 th ventricle.

When patients were reviewed according to their preoperative mRS score, 7 (58.5\%) cases had a favorable score, while 11 cases (92\%) demonstrated a favorable postoperative outcome. Five cases $(41.5 \%)$ had a preoperative morbidity score, whereas 1 case $(8 \%)$ had the same score postoperatively. In one case in which the hematoma had ruptured into the fourth ventricle, the presence of CSF surrounding the incompressible intraventricular clot was noted, and obstructive hydrocephalus was observed at a later time.

\section{Postoperative Complications}

\section{Re-hemorrhage}

Re-hemorrhage is considered the most common reason for mortality (1). There are many studies on posterior fossa
AVMs that demonstrate a correlation between the incidence of hemorrhage and an increased risk of subsequent rupture $(6,10,11,12,17,24,27,34,35)$. Mast et al. (18) demonstrated very high annual ratios, up to $17.8 \%$, with respect to bleeding events in hemorrhage patients. In the present study, rehemorrhage was not observed during the follow-up period.

Postoperative recurrent hemorrhage can be fatal $(20,33)$, but death may also occur in patients treated conservatively (4). The most serious complication following posterior fossa AVM surgery is hemorrhage from residual fragments of an AVM or from insecure hemostasis. An unrecognized, small, residual AVM is most frequently the source of bleeding as the necessity to excise the AVM on a plane very close to its margin creates the potential for leaving behind small remnants of the AVM. These residual AVMs represent a significant risk of hemorrhage because they are still arterialized and frequently disconnected from their venous drainage. When considering cerebral AVMs, it is important to keep in mind that the treatment is most frequently aimed at preventing future hemorrhaging. In general, the risk of an AVM hemorrhaging, whether it has previously bled or not, is approximately 3 to $4 \%$ per year (2). Following a hemorrhage, the risk is approximately $6 \%$ during the first 6 months, after which it decreases to approximately 3 to $4 \%$ per year, which is the same hemorrhage risk for AVMs that have never bled (2). The ideal treatment for posterior fossa AVMs with hemorrhage is microsurgical excision, and we suggest that microsurgical excision immediately eliminates the risk of future hemorrhage. Therefore, in general, we recommend surgical excision of the posterior fossa AVM with the hematoma in patients who are relatively young and in good health.

\section{RADIOSURGERY}

\section{Indications:}

Stereotactic radiosurgery is ideal for small $(<3 \mathrm{~cm})$ AVMs located in critical areas of the brain, in which the morbidity of surgical excision would be considered unacceptable. It is also a good treatment choice for patients whose age or comorbidities make the risk of general anesthesia unacceptable.

\section{Disadvantages:}

Radiosurgery is not therapeutically effective for all lesions. AVMs in or adjacent to functional brain tissue have a higher risk of radiation injury. We suggest that radiosurgery cannot be effective in patients with ruptured AVM accompanied with posterior fossa hematoma because the pressure from the mass of the hemorrhage may produce a neurological deficit. Surgical evacuation of the hemorrhage will resolve that pressure and neurological deficit (24).

\section{EMBOLIZATION}

\section{Indications}

Endovascular embolization can be used to eliminate the AVM prior to microsurgery or radiosurgery, particularly if the 
AVM may have been the source of hemorrhage. Embolization can also be used to obliterate deep arterial pedicles that are inaccessible during the early surgical exposure. We frequently use embolization to reduce blood flow and to make surgery safer for AVMs that are either in or adjacent to critical areas of the brain.

\section{Disadvantages:}

Despite some preconceived notions, endovascular procedures are not truly noninvasive, innocuous, or risk-free, as emphasized above. These procedures are frequently long and uncomfortable and may require general anesthesia with all of its associated risks (17). The risks of embolization include cerebellar infarcts from inadvertent obliteration of penetrating arteries or vessels en passage, AVM rupture from occlusion of draining veins before feeding arteries, and hemorrhage from perforation of proximal arteries by either the guidewire or the microcatheters. Previous embolization is actually a negative predictor of successful AVM radiosurgery, and some consider it to be contraindicated prior to radiosurgery (24). Embolization may not be useful in patients with ruptured posterior fossa AVM accompanied with hematoma because the mass from the hemorrhage should be alleviated urgently.

\section{CONCLUSIONS}

Posterior fossa AVM with hematomas with any threatened mass effect should be operated on an urgent basis, but decision-making in the management of these hematomas requires careful consideration and interpretation of the various criteria. The configuration of the fourth ventricle on CT scans is a useful measure for the selection of the appropriate surgical procedure, compared with estimation of the size of the hematoma and/or evaluation of the quadrigeminal cistern. This study suggests that the ideal treatment for posterior fossa AVMs with hemorrhage is microsurgical excision given that that there is a correlation between hematoma volume and outcome. Neurological outcomes following surgical treatment of cerebellar AVM with hematoma is dependent on the size and anatomical position of hematoma as well as the excised nidus. These findings demonstrate the importance of surgery, and we suggest that microsurgical excision immediately eliminates the risk of future hemorrhage and alleviates the compressing effect of the hemorrhage.

\section{REFERENCES}

1. Arnaout OM, Gross BA, Eddleman CS, Bendok BR, Getch CC, Batjer $\mathrm{HH}$ : Posterior fossa arteriovenous malformations. Neurosurg Focus 26 (5): E12, 2009

2. Baskaya MK, Jea A, Heros RC, Javahary R, Sultan A: Cerebral arteriovenous malformations Clin Neurosurg 53:114-144, 2006

3. Batjer $\mathrm{H}$, Samson D: Arteriovenous malformations of the posterior fossa: Clinical presentation, diagnostic evaluation and surgical treatment. Neurosurgical Review 9(4): 287-296, 1986

4. Brillman J: Acute hydrocephalus and death one month after nonsurgical treatment for acute cerebellar hemorrhage: Case report. J Neurosurg 50:374-376, 1979
5. Cohen ZR, Ram Z, Knoller N, Peles E, Hadani M: Management and outcome of non-traumatic cerebellar haemorrhage. Cerebrovascular Dis 14:207-213, 2002

6. da Costa L, Wallace MC, Ter Brugge KG, O'Kelly C, Willinsky RA, Tymianski $M$ : The natural history and predictive features of hemorrhage from brain arteriovenous malformations. Stroke 40:100-105, 2009

7. Deruty R, Turjman F, Pelissou-Guyoyat I: Surgical Management of Cranial Arteriovenous Malformations. Schmidek $\mathrm{HH}$, ed. Operative Neurosurgical Techniques, volume 2, fourth edition, Philadelphia: WB Saunders, 2000:1380-1391

8. Drake CG, Friedman AH, Peerless SJ: Posterior fossa arteriovenous malformations. J Neurosurg 64(1):1-10, 1986

9. Fullerton $\mathrm{HJ}$, Achrol AS, Johnston SC, McCulloch CE, Higashida RT, Lawton MT: Long-term hemorrhage risk in children versus adults with brain arteriovenous malformations. Stroke 36:20992104, 2005

10. Halim AX, Johnston SC, Singh V, McCulloch CE, Bennett JP, Achrol AS, Sindel S, Young WL: Longitudinal risk of intracranial hemorrhage in patients with arteriovenous malformation of the brain within a defined population. Stroke 35:1697-1702, 2004

11. Heiskanen O: Treatment of spontaneous intracerebral and intracerebellar hemorrhages. Stroke 24(12):94-95,107-108,1993

12. Hernesniemi JA, Dashti $R$, Juvela $S$, Vaart $K$, Niemela $M$, Laakso A: Natural history of brain arteriovenous malformations: A longterm follow-up study of risk of hemorrhage in 238 patients. Neurosurgery 63:823-831, 2008

13. Itoyama Y, Uemura S, Ushio Y, Kuratsu J, Nonaka N, Wada H, Sano Y, Fukumara A, Yoshida K, Yano T: Natural course of unoperated intracranial arteriovenous malformations: Study of 50 cases. J Neurosurg 71:805-809, 1989

14. Kelly ME, Guzman R, Sinclair J: Multimodality treatment of posterior fossa arteriovenous malformations. J Neurosurg 108(6):1152-1161, 2008

15. Khaw AV, Mohr JP, Sciacca RR, Schumacher HC, Hartmann A, Pile-Spellman J, Mast H, Stapf C: Association of infratentorial brain arteriovenous malformations with hemorrhage at initial presentation. Stroke 35:660-663, 2004

16. Kirillos R, Tyagi AK, Ross SA, Van Hille PT: Management of spontaneous cerebellar hematomas: A prospective treatment protocol. Neurosurgery 49(6): 1378-1387, 2001

17. Martin NA, Khanna R, Doberstein C, Bentson J: Therapeutic embolization of arteriovenous malformations: The case for and against. Clin Neurosurg 46:295-318, 2000

18. Mast $H$, Young WL, Koennecke HC, Sciacca RR, Osipov A, PileSpellman J, Hacein-Bey L, Duong H, Stein BM, Mohr JP: Risk of spontaneous haemorrhage after diagnosis of cerebral arteriovenous malformation. Lancet 350:1065-1068, 1997

19. Mathew P, Teasdale G, Bannan A, Oluoch-Olunya D: Neurosurgical management of cerebellar haematoma and infarct. J Neurol Neurosurg Psychiatry 59:287-292, 1995

20. Mezzadri JJ, Otero JM, Ottino CA: Management of 50 spontaneous cerebellar haemorrhages: Importance of obstructive hydrocephalus. Acta Neurochir (Wien) 122:39-44, 1993

21. Ondra SL, Troupp H, George ED, Schwab K: The natural history of symptomatic arteriovenous malformations of the brain: A 24 year follow-up assessment. J Neurosurg 73:387-391, 1990 
22. Pérez-Núñez R, Alday JJ, Rivas A, Lagares PA, Gómez JF, Alén I, Arrese y RD Lobato: Tratamiento quirúrgico de la hemorragia intracerebral espontánea. Parte II: Hemorragia infratentorial. Neurocirugía 19:101-112, 2008

23. Perret G, Nishioka H: Report on the Cooperative Study of Intracranial Aneurysms and Subarachnoid Hemorrhage. Section VI. Arteriovenous malformations. An analysis of 545 cases of cranio-cerebral arteriovenous malformations and fistulae reported to the cooperative study. J Neurosurg 25:467-490, 1966

24. Pollock BE, Flickinger JC, Lundsford LD, Maitz A, Kondziolka D: Factors associated with successful arteriovenous malformation radiosurgery. Neurosurgery 42:1239 -1247, 1998

25. Sinclair J, Kelly ME, Steinberg GK: Surgical management of posterior fossa arteriovenous malformations. Neurosurgery 58(2): 189-201, 2006

26. Solomon RA, Stein BM: Management of arteriovenous malformations of the brain stem. J Neurosurg 64:857-864, 1986

27. Spetzler RF, Martin NA: A proposed grading system for arteriovenous malformations. J Neurosurg 65: 476-483, 1986

28. Stapf C, Mast H, Sciacca RR, Choi JH, Khaw AV, Connolly ES, Pile-Spellman J, Mohr JP: Predictors of hemorrhage in patients with untreated brain arteriovenous malformation. Neurology 66:1350-1355, 2006

29. Stefani MA, Porter PJ, terBrugge KG, Montanera W, Willinsky RA, Wallace MC: Angioarchitectural factors present in brain arteriovenous malformations associated with hemorrhagic presentation. Stroke 33:920-924, 2002
30. Steinberg GK, Stoodley MA: Surgical Management of Intracranial Arteriovenous Malformations. Schmidek HH (ed), Operative Neurosurgical Techniques, volume 2, fourth edition, Philadelphia: WB Saunders, 2000:1363-1379

31. Symon L, Tacconi L, Mendoza N, Nakalji P: Arteriovenous malformations of the posterior fossa: A report on 28 cases and review of the literature. $\mathrm{Br} J$ Neurosurg 9:721-732, 1995

32. Tew, JM Jr, Lewis Al: Honored guest presentation: Management strategies for the treatment of intracranial arteriovenous malformations. Clin Neurosurg 46:267-284, 2000

33. van Loon J, Van Calenbergh F, Goffin J, Plets C: Controversies in the management of spontaneous cerebellar haemorrhage: $A$ consecutive series of 49 cases and review of the literature. Acta Neurochir (Wien) 122:187-193, 1993

34. Weisberg LA: Acute cerebellar hemorrhage and CT evidence of tight posterior fossa. Neurology 36:858-860, 1986

35. Yamada S, Takagi Y, Nozaki K, Kikuta K, Hashimoto N: Risk factors for subsequent hemorrhage in patients with cerebral arteriovenous malformations. J Neurosurg 107:965-972, 2007

36. Zhao J, Wang S, Li J, Qi W, Sui D, Zhao Y: Clinical characteristics and surgical results of patients with cerebral arteriovenous malformations. Surgical Neurology 63:156-161, 2005 